\title{
Medial Preoptic Area Afferents to Periaqueductal Gray Medullo- Output Neurons: A Combined Fos and Tract Tracing Study
}

\author{
Tilat A. Rizvi, ${ }^{2}$ Anne Z. Murphy, ${ }^{1}$ Matthew Ennis, ${ }^{1}$ Michael M. Behbehani, ${ }^{3}$ and Michael T. Shipley ${ }^{1}$ \\ ${ }^{1}$ Department of Anatomy, University of Maryland School of Medicine, Baltimore, Maryland 21201, and 2Departments of \\ Cell Biology, Neurobiology, and Anatomy and ${ }^{3}$ Molecular and Cellular Physiology, University of Cincinnati College of \\ Medicine, Cincinnati, Ohic 45267
}

\begin{abstract}
We have shown recently that the medial preoptic area (MPO) robustly innervates discrete columns along the rostrocaudal axis of the midbrain periaqueductal gray (PAG). However, the location of PAG neurons responsive to MPO activation is not known. Anterograde tract tracing was used in combination with Fos immunohistochemistry to characterize the MPO $\rightarrow$ PAG pathway anatomically and functionally within the same animal. Focal electrical or chemical stimulation of MPO in anesthetized rats induced extensive Fos expression within the PAG compared with sham controls. Fos-positive neurons were organized as 2-3 longitudinal columns. The organization and location of these columns overlapped remarkably well with the distribution of fibers and terminals in PAG labeled by Phaseolus vulgaris leucoagglutinin (PHA-L) injected into the same MPO stimulation site. This indicates that MPO inputs may terminate on the soma or proximal dendrites of neurons exhibiting elevated Fos. A
\end{abstract}

second series of experiments investigated whether MPO stimulation excited PAG neurons with descending projections to the medulla. Retrograde labeling of PAG neurons projecting to the medial and lateral regions of the rostroventral medulla (RVM) was combined with MPO-induced Fos expression. The results showed that a substantial population $(37-53 \%)$ of Fos-positive PAG neurons projected to the ventral medulla. This indicates that MPO stimulation engages PAG-medullary output neurons. Taken together, these results suggest that the MPO $\rightarrow$ PAG $\rightarrow$ RVM projection constitutes a functional pathway. This circuit may coordinately regulate neuroendocrine, motor, and autonomlc adjustments necessary for the elaboration of sexual behaviors.

Key words: reproduction; antinociception; cardiovascular regulation; brainstem; sexual behavior; immunohistochemistry
The medial preoptic area (MPO) is a sexually dimorphic structure (Gorski et al., 1980; Simerly et al., 1984; Bloch and Gorski, 1988) that plays a pivotal role in sexual behavior and neuroendocrine function (Lisk, 1966; Powers and Valenstein, 1972; Pfaff and Sakuma, 1979; Hansen et al., 1982; Arendash and Gorski, 1983; Kalra and Kalra, 1983; Docke et al., 1984; Sachs and Meisel, 1988; Simerly et al., 1990; DonCarlos et al., 1991; Takeo et al., 1993; Hoshina et al., 1994). We recently reported that MPO robustly innervates the midbrain periaqueductal gray (PAG) (Rizvi et al., 1992) and terminates in discrete, longitudinally organized columns running through the rostrocaudal axis of PAG.

PAG plays a key role in antinociception (Reynolds, 1969; Liebeskind et al., 1973; Oliveras et al., 1974; Behbehani and Fields, 1979; Lovick, 1985; Morgan and Liebeskind, 1987; Reichling et al., 1988; Lovick, 1990), cardiovascular control (Lovick, 1985; Carrive et al., 1987; Carrive et al., 1988; Carrive et al., 1989a; Lovick, 1990; Verberne and Guyenet, 1992; Murphy et al., 1994a; Murphy et al., 1995), and many of the same neuroendocrine and reproductive functions as MPO (Pfaff and SchwartzGiblin, 1988; Ogawa et al., 1991; Shipley et al., 1995). PAG neurons involved in these functions also are organized in a columnar manner (for review, see Bandler and Shipley, 1994). It is

\footnotetext{
Received May 30, 1995; revised Aug. 9, 1995; accepted Aug. 16, 1995.

This research was supported by National Institutes of Health Grants NS20643, NS24698, NS29218, HL08851, and NS29635. We thank Maorong Jiang and Lydia Hu for technical assistance.

Correspondence should be addressed to Dr. Michael T. Shipley, Department of Anatomy, University of Maryland School of Medicine, 655 West Baltimore Street, Raltimore, MD 21201.

Copyright $₫ 1995$ Society for Neuroscience $\quad 0270-6474 / 95 / 160333-12 \$ 05.00 / 0$
}

reasonable to suggest, therefore, that MPO's role in sexual behavior is mediated, at least in part, by its outputs to PAG.

Thus, it is of interest to determine whether PAG cells activated by MPO stimulation are localized discretely within the PAG and, if so, what the distribution of these cells is in relation to MPO inputs. Two extreme pussibilities exist. (1) PAG neurons activated by MPO efferents may be restricted to the columns targeted by MPO terminals. This would suggest that discrete columns of MPO terminals function, in part, to focus the physiological influence of MPO onto equally discrete sets of target cells in PAG. (2) MPO inputs also might activate widely distributed PAG neurons with dendritic arbors that extend into MPO terminal columns or interneurons, which in turn activate widely distributed output neurons. This would suggest that neurons throughout PAG integrate inputs from multiple afferent terminal columns.

An additional question is whether MPO stimulation activates PAG output neurons. If so, then MPO synaptic relays in PAG may comprise requisite links that mediate, at least in part, MPO influences on medullary circuits. To address these issues, we combined MPO stimulation-induced Fos expression with anterograde tracing from MPO and, in separate experiments, with retrograde labeling of PAG neurons projecting to the rostral ventral medulla (RVM).

\section{MATERIALS AND METHODS}

Fos expression in PAG after stimulation of $M P O$

Electrical stimulation. Male Sprague-Dawley rats (Zivic Miller) weighing $250-350 \mathrm{gm}$ were anesthetized with chloral hydrate $(400 \mathrm{mg} / \mathrm{kg}$, i.p. $)$ and placed in a stereotaxic apparatus with the skull flat. A bipolar stimulation electrode (125 $\mu \mathrm{m}$ diameter), insulated except for bluntly cut tips, was 
inserted into MPO (7.1 $\mathrm{mm}$ anterior to lambda, $0.6 \mathrm{~mm}$ lateral to midline, $6.5-7.5 \mathrm{~mm}$ ventral to the skull surface). The MPO was stimulated at 30 $\mathrm{Hz}$ (5 sec on, $3 \mathrm{sec}$ off duty cycle; $500 \mu \mathrm{A} ; 0.5 \mathrm{msec}$ pulse duration) for 1 hr. A $1 \mathrm{hr}$ epoch of stimulation was selected because our previous studies of the diagonal band nucleus to piriform cortex projection demonstrated that 45-60 min of electrical stimulation was the minimum necessary to produce a strong, consistent pattern of Fos expression in all animals (Zimmer et al., 1993). This is consistent with findings by others that expression of c-fos mRNA peaks within 30-60 min after increased neuronal activity, whereas Fos-like protein is detectable after $1 \mathrm{hr}$ (Sharp et al., 1991). Animals were perfused $30 \mathrm{~min}$ after the termination of MPO stimulation. Control animals were anesthetized and treated in an identical manner except that no current was applied through the stimulation electrode.

Chemical stimulation. Rats were anesthetized and placed in a stereotaxic apparatus, as described above. A glass micropipette $(25-50 \mu \mathrm{m}$ tip diameter) filled with a solution of $50 \mu \mathrm{M}$ bicuculline methiodide and $10 \mathrm{mM}$ D,L-homocysteate in $0.9 \%$ saline was advanced into MPO. Fifty nanoliter boluses of the solution were pressure-injected into MPO every $15 \mathrm{~min}$ for $1 \mathrm{hr}$ (five injections). D,L-Homocysteate is an excitatory amino acid that potently increases neuronal firing rates. However, D,L-homocysteate also could activate inhibitory GABAergic interneurons, which may decrease the net excitation of MPO output neurons. Thus, bicuculline, a GABA $A_{A}$ receptor antagonist, was coinjected to block any increases in inhibitory GABAergic transmission produced by $D, L-h o m o c y s t e a t e$. Animals were perfused 30 min after the last injection.

Fos immunohistochemistry. Animals were given an overdose of chloral hydrate and perfused on ice with $100 \mathrm{ml}$ of cold physiological saline followed by 1 liter of $4 \% p$-formaldehyde in $0.1 \mathrm{M}$ phosphate buffer (PB), $4^{\circ} \mathrm{C}$. Brains were removed and postfixed in the same solution for $90 \mathrm{~min}$ and then cryoprotected in $20 \%$ sucrose in $0.1 \mathrm{M}$ PB for $24 \mathrm{hr}$. Transverse sections were cut at $30 \mu \mathrm{m}$ using a freezing microtome. Fos immunohistochemistry was performed using standard avidin-biotin techniques (Hsu et al., 1981) as described previously (Murphy et al., 1994b, 1995). Briefly, sections were incubated in $2 \%$ normal rabbit serum (NRS; Vector) containing $0.2 \%$ Triton $\mathrm{X}-100$ in PBS (PBST) for $60 \mathrm{~min}$, and then incubated overnight at $4^{\circ} \mathrm{C}$ in sheep anti-Fos in PBST with $2 \%$ NRS. After rinsing, sections were incubated for $1.5 \mathrm{hr}$ in biotinylated rabbit anti-sheep IgG (1:200 dilution; Vector) in PBST containing 2\% NRS, rinsed in PBST, and then placed for $1.5 \mathrm{hr}$ in avidin-biotin peroxidase complex (ABC-Vectastain Elite Kit; Vector) at a 1:100 dilution in PBST. Fos immunoreactivity was visualized as a brown reaction product by diaminobenzidine tetrahydrochloride (DAB) in a $0.5 \%$ solution containing $0.003 \%$ hydrogen peroxide. Sections wcre mounted onto gelatinized slides out of $0.05 \mathrm{M} \mathrm{PB}$, air dried, dehydrated, and coverslipped.

The primary antibody to Fos oncoproteins was a sheep polyclonal antibody (Cambridge Research Biochemicals, OA-823). The antiserum was used at a 1:5000 dilution; immunohistochemical binding of the antibody was abolished by omission of the Fos antiserum from the immunostaining procedure. Sections from both experimental and control groups were reacted simultaneously with the same reagents to control for variability in the immunocytochemical processing.

Fos expression in PAG in relation to MPO terminal projections Animal preparation. The anterograde tracer Phaseolus vulgaris leucoagglutinin (PHA-L; Vector) was injected into the MPO using the protocol of Gerfen and Sawchenko (1984). A 2.5\% solution of PHA-L dissolved in $10 \mathrm{mM} \mathrm{PB}, \mathrm{pH} 8.0$, was deposited iontophoretically $(+5.0 \mu \mathrm{A}$ constant current pulses, $7 \mathrm{sec}$ on, $3 \mathrm{sec}$ off duty cycle for $20-30 \mathrm{~min}$ ) into MPO from a glass micropipette $(10-12 \mu \mathrm{m}$ tip diameter) as described previously (Rizvi et al., 1992, 1994). Typically, two injections $(7.65-7.75 \mathrm{~mm}$ ventral to the skull surface), separated dorsoventrally by $300 \mu \mathrm{m}$, were made to increase the size of PHA-L deposit. Seven days after the PHA-L injection, the animals were reanesthetized and a stimulation electrode (identical to that described above) was inserted into the MPO at the same stereotaxic coordinates used for the PHA-L injection (Fig. 1A). Stimulation procedures were identical to those described above. After stimulation, animals were perfused and the brains were processed for immunohistochemistry.

Double labeling of Fos and PHA-L. Sections were incubated at room temperature in $4-5 \%$ NRS in PBST for $1 \mathrm{hr}$. Sections were then incubated $(24 \mathrm{hr})$ in a cocktail of two primary antibodies: goat anti-PHA-L (Vector; 1:16,000-18,000 dilution) and sheep anti-Fos (Cambridge Research Biochemicals; 1:5000 dilution) in PBST containing 5\% NRS at $4^{\circ} \mathrm{C}$. After incubation, sections were rinsed in PBST and then incubated
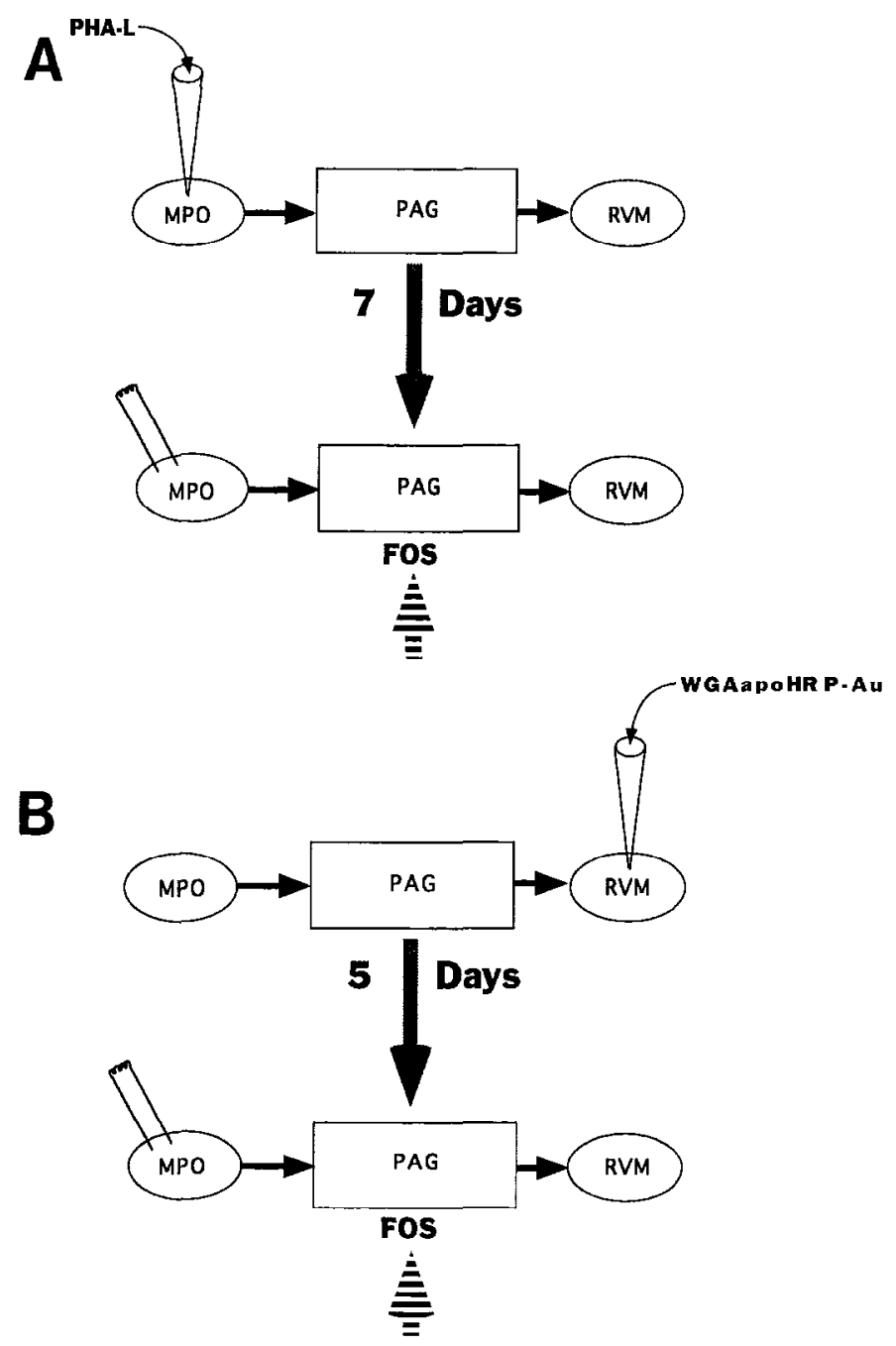

Figure 1. Schematic diagrams of experimental designs. $A$, The anterograde tracer PHA-L was iontophoretically deposited in the MPO. Seven days later, animals were reanesthetized and a stimulation electrode was lowered into the same MPO site. MPO was electrically stimulated for $1 \mathrm{hr}$ (see Materials and Methods). $B$, The retrograde tracer WGAapoHRP-AU was microinjected into the NRM and nucleus PGi. Five days later, MPO was electrically stimulated.

for $1 \mathrm{hr}$ in a mixture of two secondary antibodies: rabbit anti-goat and rabbit anti-sheep IgG (Vector; 1:200 dilution) in PBST containing 5\% NRS. Sections were then rinsed in PBST, incubated in avidin-biotin peroxidase complex (ABC-Vectastain Elite Kit, Vector) for $1 \mathrm{hr}$, and then rinsed in PBST. Sections were reacted in a solution containing $0.05 \%$ DAB and $0.003 \%$ hydrogen peroxide. Sections were mounted onto gelatinized slides out of $0.05 \mathrm{M} \mathrm{PB}$, air dried, dehydrated, cleared in xylene, and coverslipped using DPX. PHA-L staining was visualized in fibers and terminals, whereas Fos staining was restricted to the cellular nucleus.

\section{Fos expression in PAG in relation to medullary projection neurons}

Animal preparation. To retrogradely label PAG neurons projecting to the medulla, injections of WGAapoHKP-AU (WGA-AU) were made in two rostral ventral medullary sites previously shown to be targeted heavily by PAG (Van Bockstaele et al., 1991) (Fig. 1B). WGA-AU was prepared in a way similar to the protocol described by Menétrey and Basbaum (1989). Glass micropipettes (20-30 $\mu \mathrm{m}$ tip diameter) filled with WGA-AU were advanced into (1) the nucleus raphe magnus (NRM) (3.2-3.5 mm posterior to lambda, midline and $8.0-8.5 \mathrm{~mm}$ ventral to the skull surface), located within the medial RVM and (2) the nucleus paragigantocellularis (PGi) $(4.0-4.5 \mathrm{~mm}$ posterior to lambda, $1.5-2.0 \mathrm{~mm}$ from the midlinc and $8.0-8.2 \mathrm{~mm}$ ventral to the skull surface), located in the lateral RVM. 
A $200-300 \mathrm{nl}$ bolus of WGA-AU was ejected at each ventromedial and ventrolateral site using a hydraulic pressure injection device.

Five days after WGA-AU injections, the animal was reanesthetized and a stimulation electrode was inserted into the MPO as described above (see Fig. $1 B$ ). After stimulation, animals were perfused and the brains processed for immunohistochemistry. Thirty-to-forty-micrometer-thick sections were cut on a freezing microtome, and a silver reaction (IntenSE M Silver Enhancement Kit, Amersham) was performed as follows: (1) sections were rinsed $2 \times 5 \mathrm{~min}$ in PB; (2) washed twice rapidly in double-distilled water; (3) incubated for $30 \mathrm{~min}$ in a $1: 1$ mixture of solution A (initiator) and solution B (enhancer); (4) washed twice rapidly in double-distilled water; and (5) rinsed $2 \times 5$ min in PB. The sections were then processed for Fos immunohistochemistry as described above.

\section{Data analysis}

Chartings of injection and stimulation sites, and labeled cells. Fos-labeled nuclei, anterogradely labeled fibers and terminals, and retrogradely labeled cells were plotted using a video-computer image analysis system (Shipley et al., 1989). Sections were examined at 4-40× magnification under both bright- and dark-field optics using a Nikon Microphot-FX microscope. Cells containing black punctate granules were considered retrogradely labeled; cells containing a brown nucleus that were clearly differentiated from the unstained nucleolus were considered Fos-positive; and cells containing a brown nucleus with black granules present in the cytoplasm were considered double-labeled.

Cell counting. Quantitative counts of Fos-positive, retrogradely labeled, and double-labeled cells were obtained from the video-computer image charts. Counts were made on the side of the brain ipsilateral to MPO stimulation and retrograde tracer injections.

\section{RESULTS}

\section{Expression of Fos in PAG after activation of MPO: comparison of electrical versus chemical stimulation}

As shown in Figures 2-5, electrical activation of MPO produced robust expression of Fos throughout the entire rostrocaudal axis of PAG. The second method of activating MPO neurons in this study, injections of D,L-homocysteate and bicuculline (see Materials and Methods) into MPO $(n=6)$, also increased Fos expression in PAG dramatically. As illustrated for one level of PAG (Fig. 2), the patterns of Fos expression produced by these two stimulation methods were remarkably similar. Overall, greater numbers of Fos-positive neurons and more intense Fos staining were produced by electrical than by chemical stimulation of MPO. The finding that the patterns of Fos expression produced by electrical and chemical stimulation were essentially identical indicates that Fos staining produced by electrical stimulation was not mediated by fibers of passage. It is also unlikely that antidromic activation contributed significantly to the observed Fos labeling, because although some PAG neurons project to MPO (Rizvi et al., 1992), these neurons are not organized into the columnar patterns observed here. Therefore, because electrical stimulation was a more consistent method for activating Fos in PAG neurons, this method was used in the double-labeling experiments described next. Finally, as shown in Figure 3, very few Fos-positive cells were present in the PAG of sham animals that had stimulation electrodes inserted into the MPO but received no electrical stimulation $(n=5)$. Thus, anesthesia, surgery, and stimulation electrode implantation do not produce appreciable Fos staining in PAG.

\section{Expression of Fos in PAG after electrical stimulation of MPO: relationship to MPO terminals and fibers}

Injection and stimulation sites were centered within the central, medial, and lateral MPO regions. These regions previously have been shown to contain a high density of PAG projection neurons (Rizvi et al., 1992). The location of PHA-L deposits was determined by the degree to which the stimulation electrode was
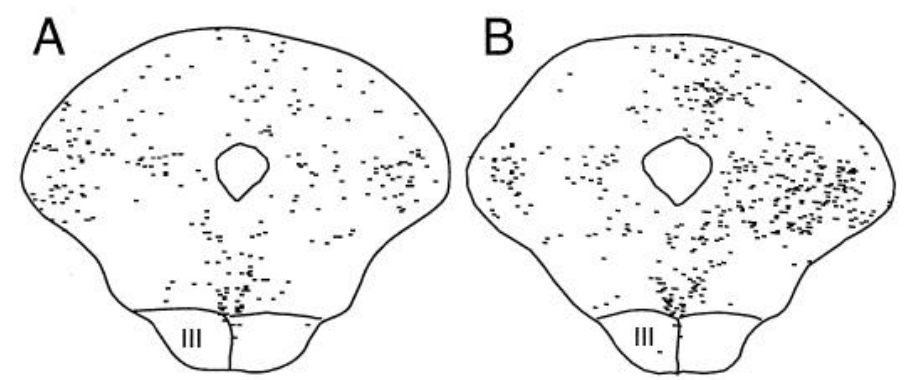

Figure 2. Video-computer-assisted plots showing the distribution of Foslabeled cells in PAG at the level of the oculomotor nucleus produced by chemical $(A)$ and electrical $(B)$ stimulation of MPO.
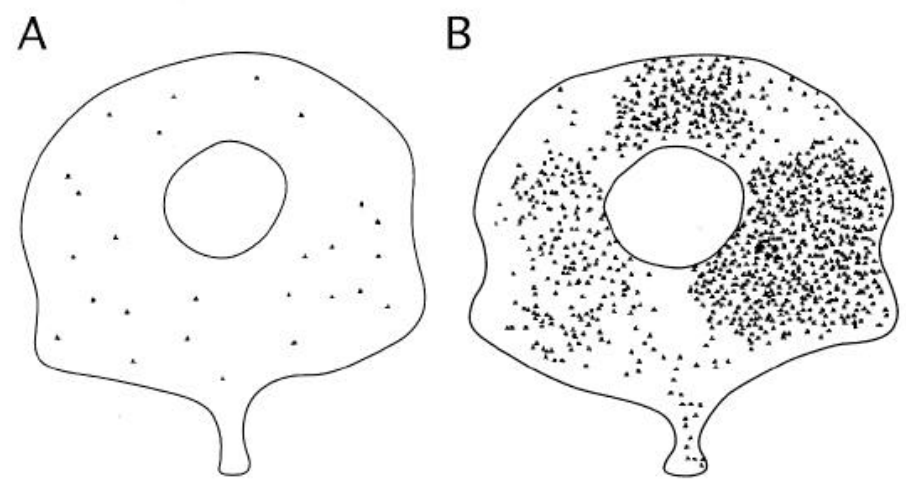

Figure 3. Video-computer-assisted plots of the distribution of Foslabeled cells at midcaudal level of PAG in a sham control brain $(A)$ and an MPO electrical stimulation brain $(B)$.

centered within the dense central core of the injection site. As shown in Figure $4 A$, the stimulation site essentially bisected the core of the PHA-L deposit in MPO. Taken together with the finding that this injection produced a dense anterograde labeling in PAG (described below) in a pattern identical to that produced by injections restricted to the central part of MPO (Rizvi et al., 1992, 1994), we conclude that the injection site was centered in MPO.

MPO stimulation $(n=6)$ dramatically increased the number of PAG cells expressing Fos compared with sham controls (Fig. 3). Fos expression induced by MPO stimulation was concentrated in 2-3 longitudinally organized columns of neurons that extended through dorsomedial, lateral, and ventrolateral PAG (Fig. 5, left). MPO fibers and terminals were distributed in 2-3 rostrocaudally oriented columns that overlapped remarkably well with the Fos columns (Fig. 5, right). By contrast, there was very little Fos expression or anterograde labeling in dorsolateral PAG at midto-caudal levels of this structure (Fig. $5 C-E$ ). Although both Fos expression and anterograde labeling were bilateral, there was a marked ipsilateral predominance.

Within the rostral pole of PAG at the level of the periventricular gray (Fig. 5A), intense Fos labeling was present alongside the lateral walls of the cerebral aqueduct and in ventromedial PAG. This distribution overlaps significantly with the pattern of projections from the MPO. At the level of Edinger-Westphal nucleus (Fig. 5B), Fos expression was densest in the dorsomedial, dorsolateral, and lateral PAG; these same regions were targeted heavily by MPO efferents. By contrast, there was relatively little Fos staining or anterograde labeling in the ventral PAG or in the nucleus of Darkschewitsch and the Edinger-Westphal nucleus, located in ventromedial PAG. At the level of oculomotor nucleus 

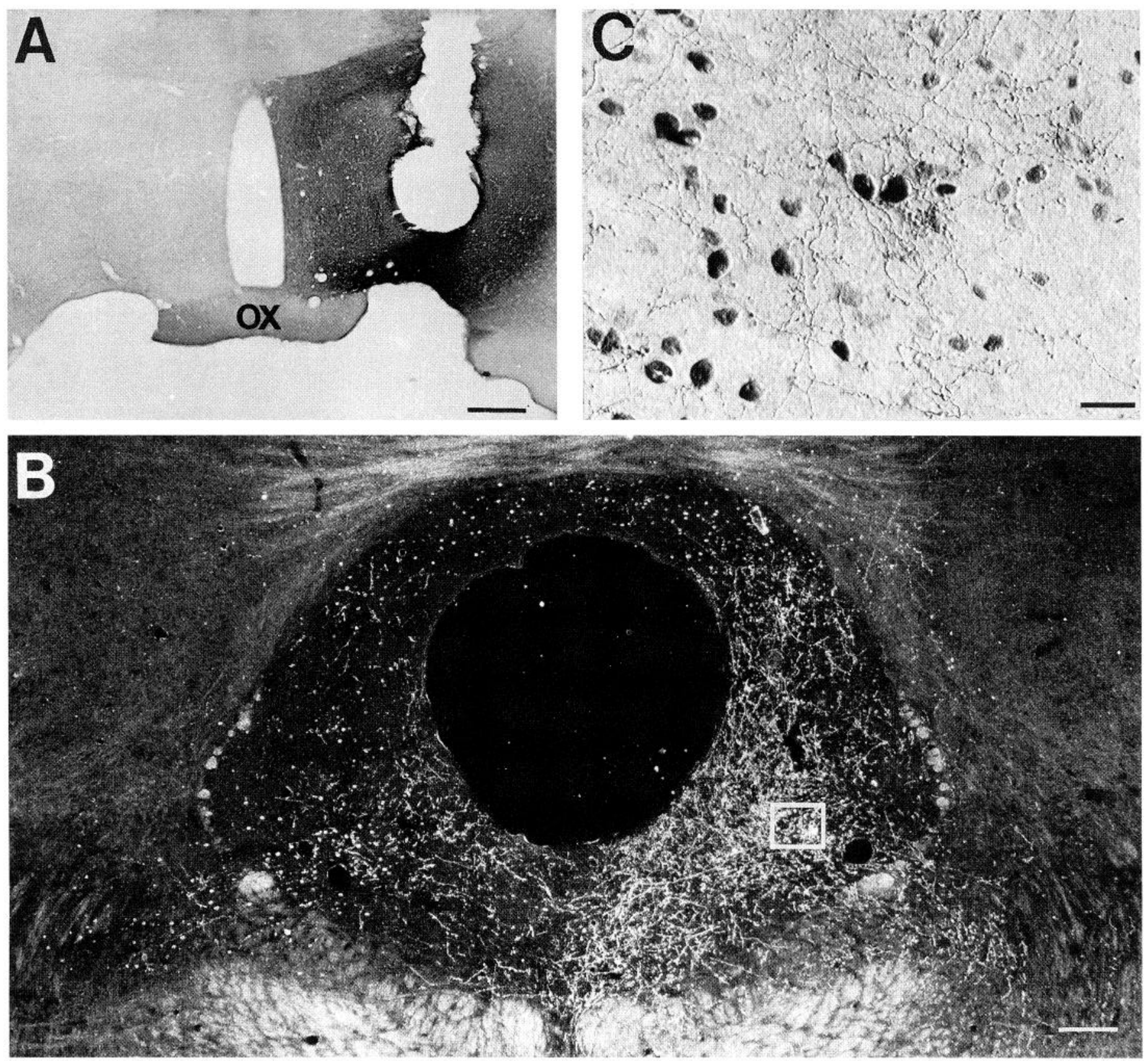

Figure 4. A, Coronal section of the MPO showing the location of the PHA-L deposit and the electrode placement for electrical stimulation of MPO. Injection and stimulation sites involved medial, central, and lateral parts of MPO, including the medial preoptic nucleus. Scale bar, $270 \mu \mathrm{m}$. $B$, Dark-field photomicrograph of a PAG coronal section showing the high degree of correspondence in the distribution of fibers and terminals anterogradely labeled from a PHA-L deposit in MPO, and Fos expression induced by MPO stimulation. Scale bar, $490 \mu \mathrm{m}$. $C$, High-power photomicrograph showing the high degree of overlap in the distribution of PHA-L-labeled fibers and terminals and Fos expression. ox, optic chiasm. Scale bar, $25 \mu \mathrm{m}$.

(Fig. $5 C$ ), intense Fos expression was restricted to two discrete regions within the lateral and dorsomedial PAG; MPO axons and terminals were organized in an identical columnar manner. A narrow band of Fos-positive cells and PHA-L anterograde labeling were situated along the midline ventral PAG. Notably, the dorsolateral and ventrolateral divisions of PAG were devoid of both types of labeling. At midlevels of PAG corresponding to the level of the trochlear nucleus (Fig. $5 D$ ), heavy Fos expression continued in the two columns of neurons extending through the dorsomedial and lateral PAG. This pattern of Fos labeling corresponds remarkably well to the afferent terminal columns from
MPO. At this level, the distribution of Fos-positive cells and PHA-L anterograde labeling within the lateral column of PAG increases in size and extends partially into the ventrolateral PAG. The dorsolateral and ventromedial regions contained only a few or no Fos-labeled nuclei or PHA-L-labeled fibers and terminals. At the level of the rostral dorsal raphe (Fig. $5 E$ ), both Fos-positive cells and MPO anterogradely labeled fibers and terminals were localized primarily within the dorsomedial, lateral, and ventrolateral PAG. In addition, there was an increase in the number of Fos-positive cells within the dorsolateral PAG. Figure 4, $B$ and $C$, shows an example of the high degree of overlap in the two 


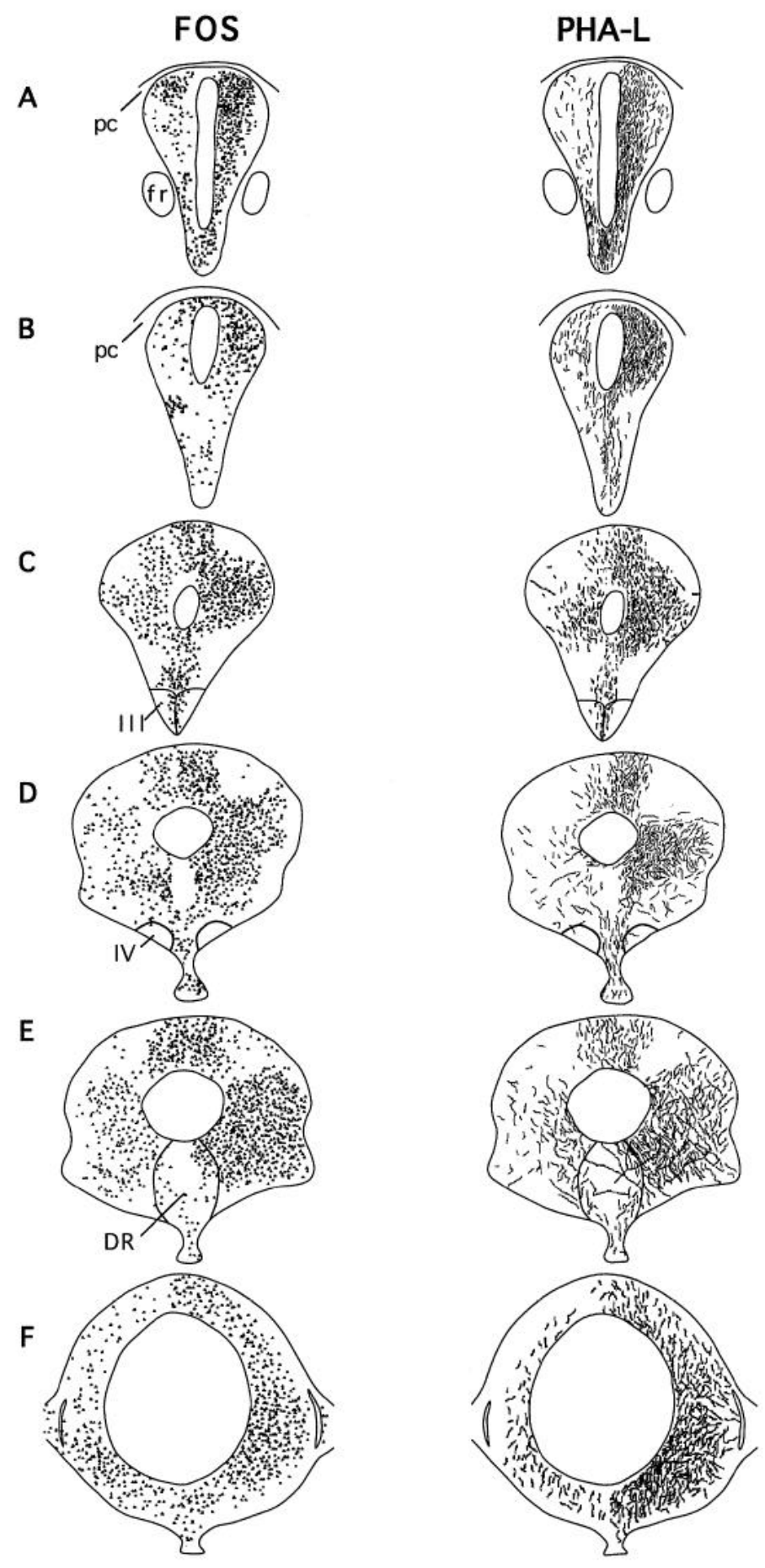

Figure 5. Fos expression and PHA-L labeling in PAG. Computer-video lucida drawing of sections taken through the PAG from rostral $(A)$ to caudal $(F)$ showing the distribution of MPO stimulation-induced Fos expression (left) and fibers and terminals anterogradely labeled from MPO (right). Fos and PHA-L labeling at each corresponding level in the two columns were plotted from the same sections but are shown in separate drawings to facilitate comparison. $f r$, fasciculus retroflexus; $p c$, posterior commissure; $I I I$, oculomotor nucleus; $I V$, trochlear nucleus; $D R$, dorsal raphe.

distributions. Very few Fos-positive cells or MPO fibers and terminals were present within the ventromedial PAG-dorsal raphe region. Within the caudal pole of PAG at the level of the nucleus cuneiformis-inferior colliculus (Fig. $5 F$ ), Fos staining was distributed throughout the PAG with the densest staining local- ized within the ventrolateral PAG; this distribution was the same as that of MPO fibers and terminals.

\section{Expression of Fos in PAG after electrical stimulation of MPO: relationship to PAG medullary output neurons}

Injections of WGA-AU into the NRM and nucleus PGi $(n=3)$ retrogradely labeled a large population of neurons along the rostrocaudal axis of PAG. Figure 6 shows an example of a WGA-AU injection into the NRM (Fig. $6 A$ ) and the nucleus PGi (Fig. 6B). Double-labeling studies with Fos and WGA-AU revealed that $36-53 \%$ of all Fos-labeled PAG neurons were retrogradely labeled from the medulla (Table 1). Double-labeled cells comprised 2-3 longitudinally oriented columns that extended along the rostrocaudal axis of PAG.

Figure 7 shows the distribution of MPO-induced Fos expression and cells retrogradely labeled from the medulla along the rostrocaudal axis of PAG. As shown, both Fos- and WGA-AU-containing cells were located bilaterally within the PAG, with an ipsilateral predominance. At the level of the periventricular gray (Fig. $7 A$ ), WGA-AU-labeled cells were located throughout the dorsal half of PAG. Very few retrogradely labeled cells were present in the ventromedial PAG. Approximately $37 \%$ of Fos-positive cells at this level were double-labeled with WGA-AU. These cells were located primarily within the lateral PAG. Slightly more caudal, at the level of the Edinger-Westphal nucleus, WGA-AU-labeled cells are located throughout the PAG (Fig. 7B). At this level, $\sim 42 \%$ of all Fos-positive cells were retrogradely labeled from the medulla. Double-labeled cells are concentrated within the dorsomedial and lateral PAG. At the level of the oculomotor nucleus (Fig. 7C), WGA-AU-labeled cells are densely located throughout the PAG. Approximately $44 \%$ of Fos-positive cells were doublelabeled; these cells are located within the dorsomedial, lateral, and ventromedial PAG. Caudally (Fig. 7D), retrogradely labeled cells are located throughout the PAG, with the exception of the dorsolateral region. Approximately $43 \%$ of the Fos-positive cells at this level are double-labeled. These cells are concentrated within the lateral and ventromedial PAG. A few double-labeled cells also are present within the dorsomedial region. Conspicuously, neither WGA-AU nor Fos-positive cells were found in the dorsolateral PAG. At the level of the trochlear nucleus (Fig. $7 E$ ), retrogradely labeled cells are present in the dorsomedial, lateral, and ventrolateral PAG; very few WGA-AU-labeled cells were located in the dorsolateral or ventromedial region (Fig. 8A). Rostrally, Fos-positive and WGA-AU-labeled cells were concentrated within the lateral region of PAG; however, at this level, double-labeled cells shifted ventrally and are now located predominantly within the ventrolateral PAG. A few double-labeled cells are still present within the lateral PAG (Fig. $8 B-F$ ). At the level of the dorsal raphe (Fig. $7 F$ ), retrogradely labeled cells are located throughout the PAG, including the dorsal raphe region. Approximately $53 \%$ of all Fos-positive cells at this level were retrogradely labeled from the medulla. These cells were located primarily within the ventrolateral PAG; a few double-labeled cells also were present within the dorsomedial, dorsolateral, and lateral PAG.

\section{DISCUSSION}

Activation of MPO neurons induces extensive Fos expression within the PAG. Fos-positive cells were organized as 2-3 longitudinal columns that traversed the entire rostrocaudal axis of PAG. Within the rostral half of PAG, Fos-positive cells were concen- 


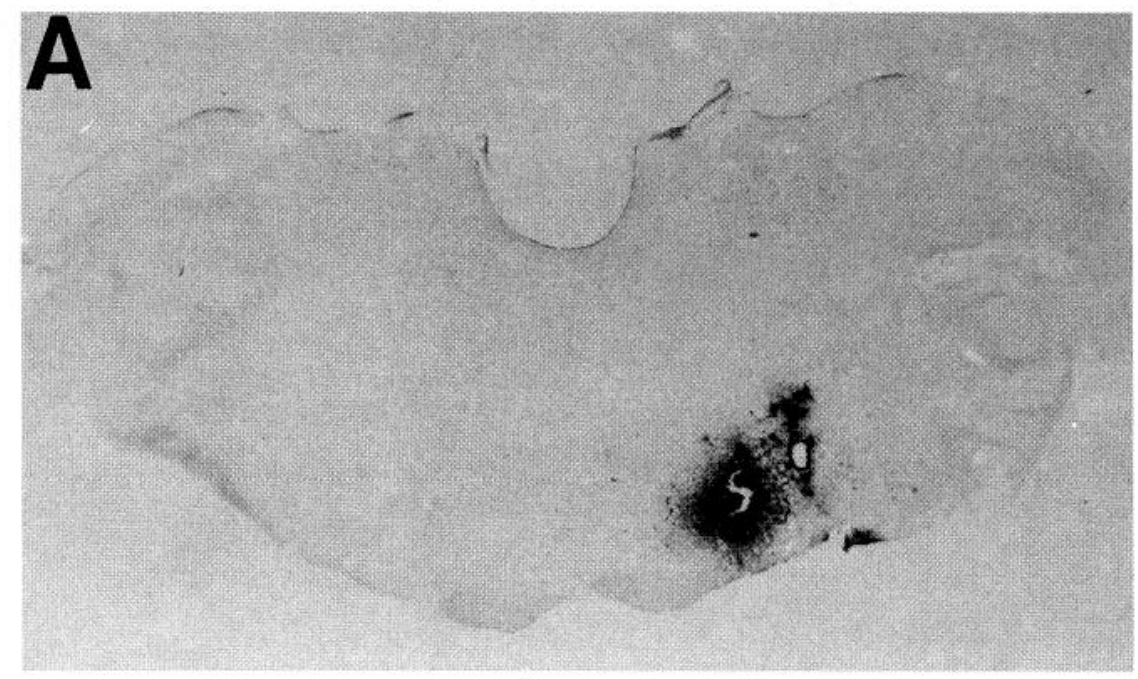

Figure 6. WGA-AU injection sites. Photomicrographs showing examples of WGA-AU injection sites centered within the nucleus PGi $(A)$ and NRM $(B)$. Scale bar, 210 $\mu \mathrm{m}$.

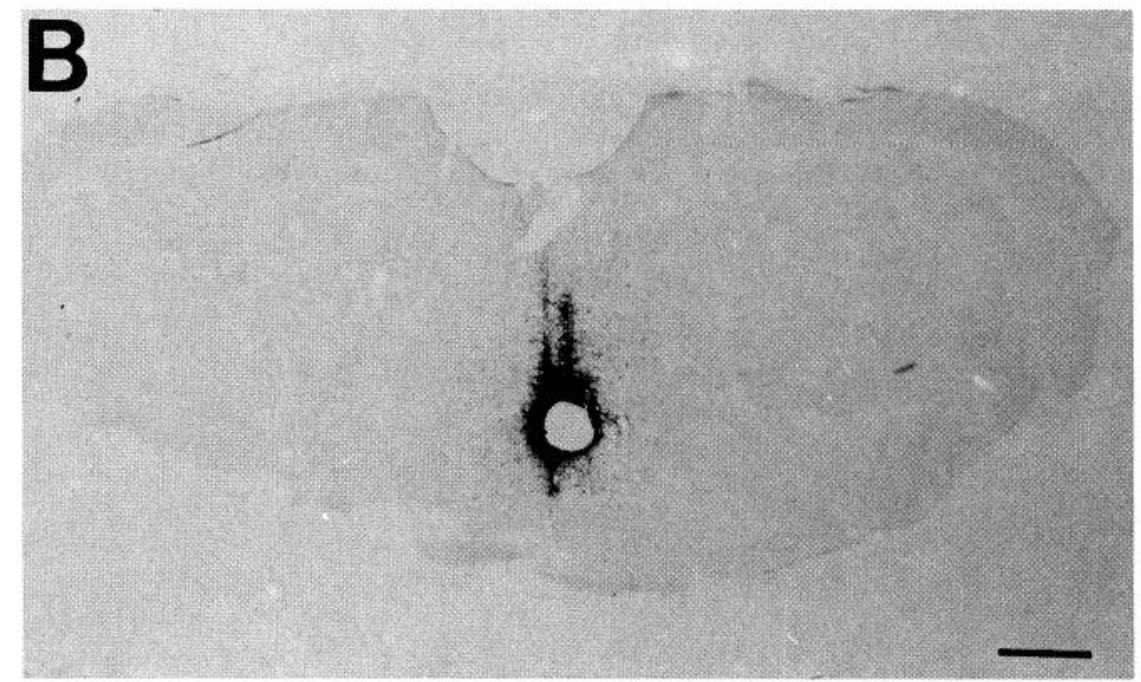

Table 1. Number of PAG cells retrogradely labeled after injection of WGA-AU into the NRM and nucleus PGi, expressing Fos after electrical stimulation of the MPO, and double-labeled with both Fos and WGA-AU for one representative animal at six rostrocaudal levels

\begin{tabular}{lllll} 
& $\begin{array}{l}\text { No. of } \\
\text { WGA-AU- } \\
\text { labeled } \\
\text { cells }\end{array}$ & $\begin{array}{l}\text { No. of } \\
\text { Fos- } \\
\text { labeled } \\
\text { cells }\end{array}$ & $\begin{array}{l}\text { No. of } \\
\text { double- } \\
\text { labeled } \\
\text { cells }\end{array}$ & $\begin{array}{l}\% \text { of } \\
\text { Fos } \\
\text { cells } \\
\text { double- } \\
\text { labeled }\end{array}$ \\
$\begin{array}{l}\text { Rostrocaudal levels of PAG } \\
\begin{array}{l}\text { Level of periventricular gray } \\
\text { Level of Edinger- }\end{array}\end{array}$ & 233 & 126 & 47 & 37 \\
$\quad$ & 261 & 102 & 43 & 42 \\
$\begin{array}{l}\text { Westphal nucleus } \\
\text { Level of red nucleus }\end{array}$ & 249 & 148 & 65 & 44 \\
$\begin{array}{l}\text { Level of oculomotor nucleus } \\
\text { Level of trochlear nucleus }\end{array}$ & 443 & 180 & 77 & 43 \\
Level of dorsal raphe & 376 & 133 & 54 & 41 \\
\hline
\end{tabular}

The percentage of Fos-positive cells that were retrogradely labeled from the medulla is also given. All cells were counted for the PAG side ipsilateral to the injection and stimulation site.

trated within the dorsomedial, lateral, and ventromedial region; in the caudal half, Fos-positive cells emerged within the ventrolateral PAG and dropped out of the ventromedial PAG. MPO projections to PAG terminate as 2-3 longitudinal columns with a remarkably similar organization to that of the Fos-positive cells
(Rizvi et al., 1992). The present double-labeling studies showed that there is a high degree of overlap between MPO terminals and PAG neurons excited by MPO stimulation. This suggests that MPO inputs terminate on neurons exhibiting elevated Fos. Although neurons in other parts of PAG may extend dendrites into MPO afferent columns, such cells do not appear to receive as strong an excitatory drive from the MPO as neurons within the MPO afferent columns. A significant population of MPO-activated, Fos-positive PAG neurons were labeled retrogradely from the medulla. This indicates that activation of MPO engages a substantial proportion of PAG neurons that project to the medulla.

\section{Fos as a functional marker}

Fos expression correlates with functional activation of neurons (Morgan and Curran, 1986; Hunt et al., 1987; Dragunow and Faull, 1989; Bullitt, 1990; Presley et al., 1990; Sheng and Greenberg, 1990; Jones and Light, 1990; Chan and Sawchenko, 1994; Erickson and Millhorn, 1994; Murphy et al., 1994b; Murphy et al., 1995) but limitations of this technique must be recognized. Fos can be induced by repeated depolarization, but some neurons may follow repetitive depolarizations better than others. Fos protein may be produced in higher quantities or degraded less rapidly in different neuronal populations. In our study, a $1 \mathrm{hr}$ stimulation period produced reliable and reproducible results, but it is possi- 


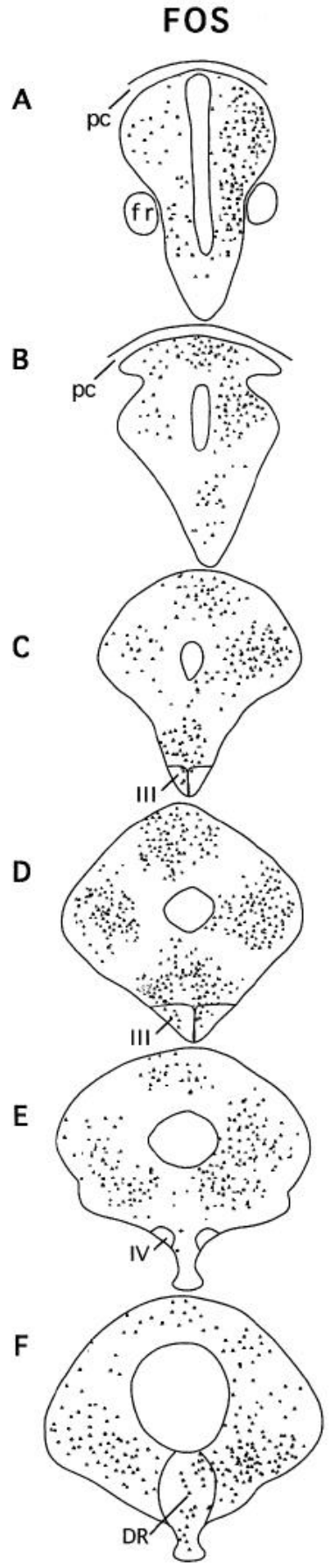

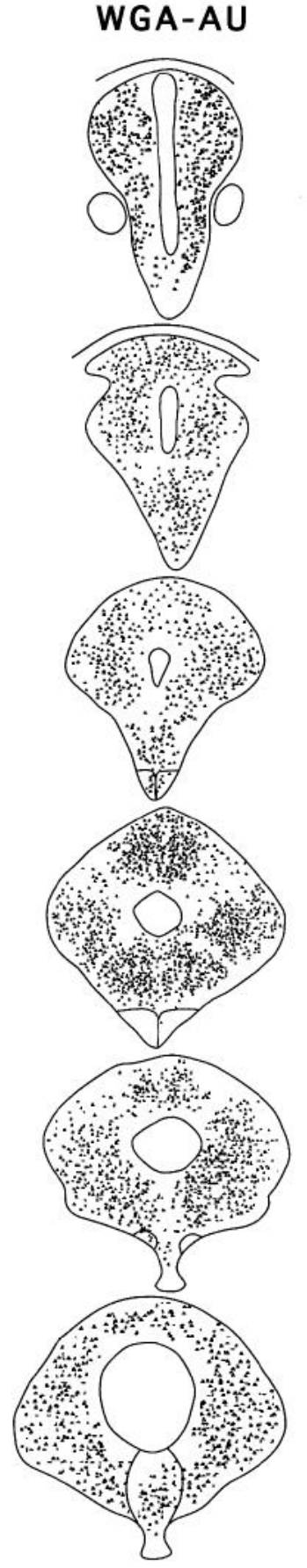

ble that different stimulation epochs and/or survival times labeled additional or different populations of cells. Anesthesia can induce and/or suppress Fos in different brain regions (Krukoff et al., 1992). In the present experiments, the type and depth of anesthesia were kept constant; moreover, very few Fos-positive cells were present in sham controls. Thus, anesthesia did not appear to substantially influence the present results.

Chemical and electrical stimulation of MPO induced similar patterns of Fos expression in PAG. This indicates PAG labeling was not significantly contaminated by electrical stimulation of fibers of passage coursing through or near MPO or by antidromic activation of PAG neurons projecting to MPO. Electrical stimulation did produce more Fos-positive cells than chemical stimulation. This may be caused by the maintained and synchronized
WGA-AU \& FOS

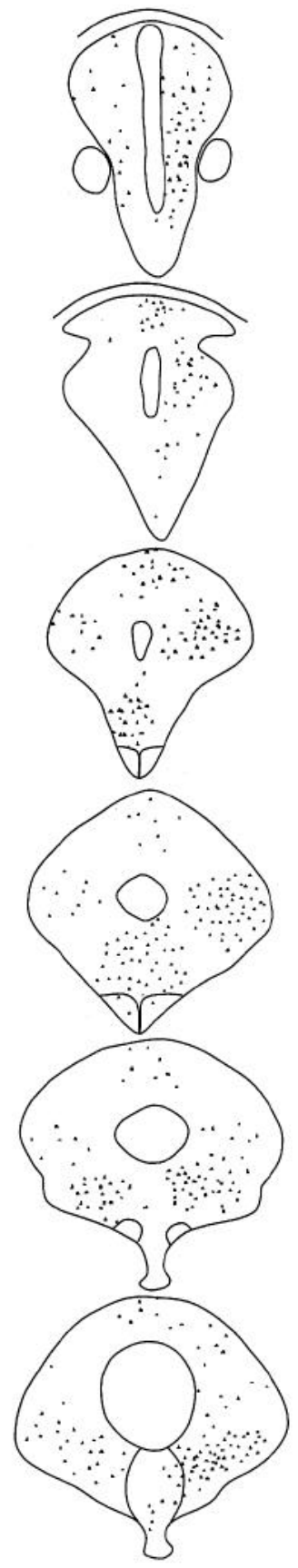

Figure 7. Fos and WGA-AU labeling in PAG. Computer-video lucida drawings of sections taken through the PAG from rostral $(A)$ to caudal $(F)$ showing the distribution of MPO stimulation-induced Fos expression (left), WGA-AU-labeled cells from the medulla (center), and cells double-labeled with Fos and WGA-AU (right). $f r$, fasciculus retroflexus; $p c$, posterior commissure; $I I I$, oculomotor nucleus; $I V$, trochlear nucleus; $D R$, dorsal raphe.

discharge in MPO neurons and axons produced by electrical stimulation. By contrast, boluses of chemical excitants may cause a transient increase followed by a decline in neuronal activity until the subsequent bolus. Also, overexcitation leading to depolarization block may decrease the efficacy of chemical stimulation. The important point, however, is that the patterns of Fos-positive PAG cells after electrical versus chemical stimulation of MPO were indistinguishable.

From the present results we cannot conclude that Fos induction in PAG-medullary output neurons was caused by monosynaptic inputs from MPO. Fos-positive neurons that were not labeled from the medulla could be interneurons that link MPO inputs to PAG-medullary output neurons. However, in view of the high degree of spatial overlap between MPO terminals and Fos- 

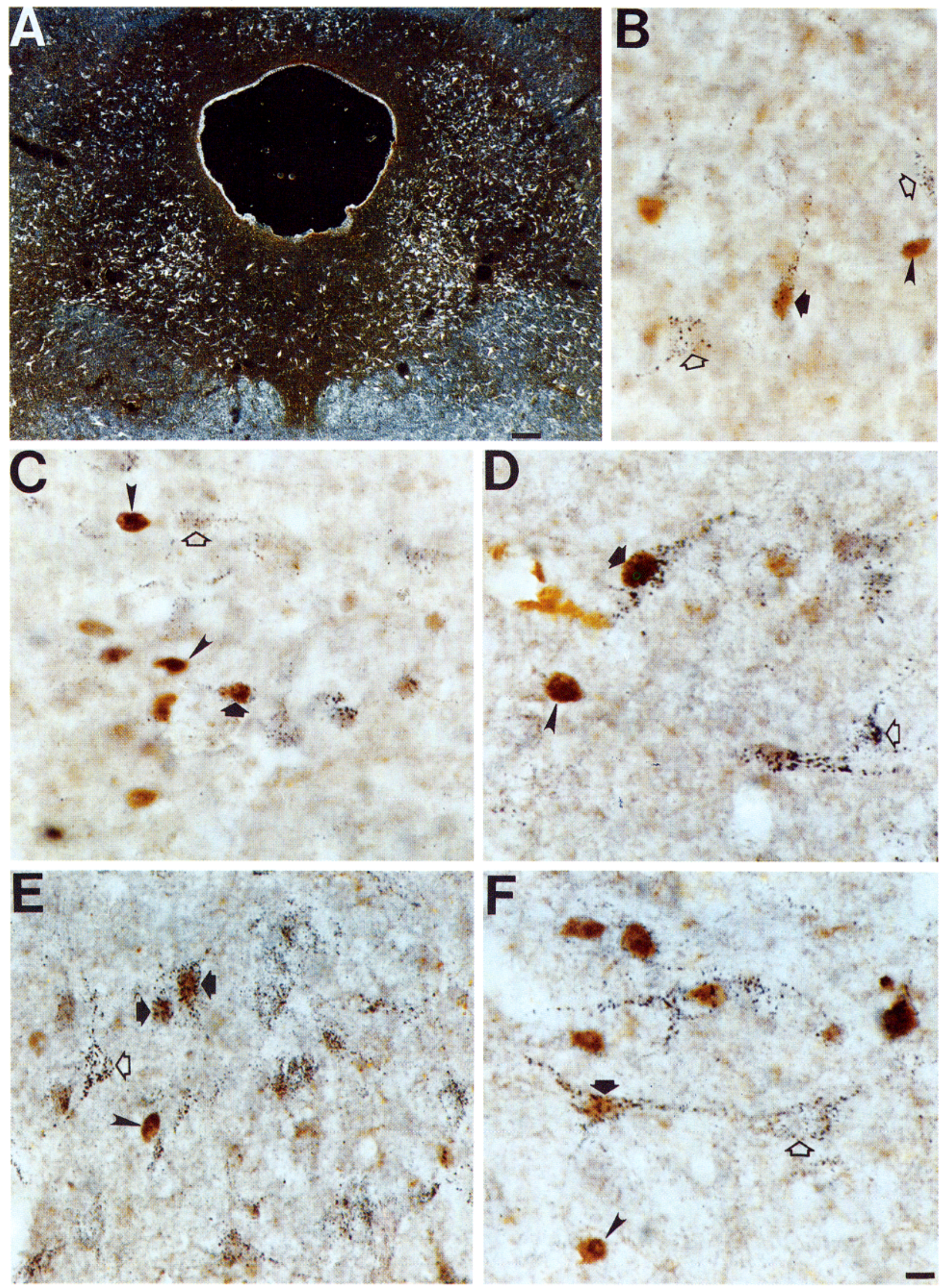

Figure 8. A, Dark-field photomicrograph of a coronal section through the PAG at the level of the trochlear nucleus showing neurons retrogradely labeled by WGA-AU injections in the medulla. At this level, labeled neurons are located primarily in dorsomedial and lateral-ventrolateral PAG. $C$ - $F$, Photomicrographs showing examples of Fos-labeled neurons (arrowheads), WGA-AU-labeled neurons (open arrows), and double-labeled neurons (solid arrows) in different regions. $B$, dorsomedial PAG; $C$, lateral PAG; $D-F$, ventrolateral PAG. 
positive PAG cells, this would imply that the discrete columns of MPO inputs are focused on equally discrete columns of local circuit neurons. On the other hand, Fos-positive neurons that were not labeled from the ventral medulla may comprise other populations of PAG output neurons that project to other brain areas. Additional experiments are necessary to resolve these alternatives.

\section{Reproductive functions of MPO}

MPO has been implicated in a variety of physiological and behavioral functions, including maternal and sex behaviors (Clemens and Gladue, 1979; Jacobson et al., 1980; Swanson and Mogenson, 1981; McCarthy et al., 1990; Mallick et al., 1994), sleep (McGinty and Szymusiak, 1990; Koyama and Hayaishi, 1994; Lin et al., 1994), thermoregulation and maintenance of water balance (Roberts and Martin, 1977; Swanson et al., 1978; Day et al., 1979; Swanson and Mogenson, 1981; Hori et al., 1988; Scammell et al., 1993; Vellucci and Parrott, 1994), antinociception (Carstens et al,, 1982), and autonomic regulation (Wang and Ranson, 1941; Mancia and Zanchetti, 1981; Swanson and Mogenson, 1981; Manning et al., 1985; O'Neill and Brody, 1987; Hori et al., 1988). MPO plays a gender-dependent role in reproductive behavior. In females, bilateral lesions of the MPO facilitate the occurrence of lordosis (Powers and Valenstein, 1972; Nance et al., 1977; Rodriguez-Sierra and Terasawa, 1979; Lisk and MacGregor, 1982; Hoshina et al., 1994); chemical or electrical stimulation of MPO suppresses it (Moss et al., 1974; Zasorin et al., 1975; Pfaff and Sakuma, 1979; Takeo et al., 1993). By contrast, in males MPO lesions completely abolish mounting, intromission, and ejaculation, whereas stimulation of this region induces copulation (Heimer and Larrson, 1966; Lisk, 1966; Malsbury et al., 1981; Hansen et al., 1982; Arendash and Gorski, 1983; Edwards and Einhorn, 1986).

\section{Integrative functions of PAG}

PAG has been strongly implicated in pain modulation (Reynolds, 1969; Liebeskind et al., 1973; Oliveras et al., 1974; Behbehani and Fields, 1979; Lovick, 1985; Reichling et al., 1988), vocalization (Jürgens and Pratt, 1979; Larson and Kistler, 1984; Larson, 1985; Larson and Kistler, 1986; Jürgens, 1991; Davis et al., 1993), blood pressure regulation (Lovick, 1985; Carrive et al., 1987; Carrive et al., 1988; Carrive et al., 1989a; Lovick, 1990; Verberne and Guyenet, 1992; Murphy et al., 1994a, 1995), regional blood flow (Bandler and Carrive, 1988; Carrive et al., 1989b; Carrive and Bandler, 1991), and mobility (Bandler and Carrive, 1988; Bandler et al., 1991). These autonomic, sensory, and behavioral adjustments are all engaged during reproductive behaviors. Both PAG and MPO have been strongly implicated in reproductive behavior. Therefore, the remarkable overlap between MPO efferents and MPO stimulation-induced, Fos-positive PAG neurons suggests that specific subsets of PAG neurons are engaged by the MPO during sexual behavior to regulate movement, vocalization, changes in heart rate, blood pressure, respiration, and pain sensitivity.

\section{Reproductive functions of PAG}

PAG has been strongly linked to female reproductive behavior (for review, see Pfaff and Schwartz-Giblin, 1988; Ogawa et al., 1991; Shipley et al., 1995). Stimulation in the dorsolateral and lateral parts of the rostral two-thirds of PAG facilitates lordosis; electrolytic lesions of these regions suppresses it (Sakuma and
Pfaff, 1979a,b). By contrast, the role of PAG in male reproductive beliavior has been largely ignored. Buth mRNA and protein for androgen and estrogen receptors are present in the male PAG (Simerly et al., 1990; Murphy et al., unpublished observations). MPO densely innervates PAG in male rats. As a substantial component of this projection arises from the sexually dimorphic medial preoptic nucleus (Simerly et al., 1984), it is possible that there are gender-based differences in MPO $\rightarrow$ PAG projections. Additional studies comparing males and females are necessary to examine this possibility. It is likely that PAG plays a pivotal role in male reproductive behavior, but additional research in this area is needed.

\section{Columnar organization in PAG}

PAG is organized into longitudinal columns (Bandler and Shipley, 1994). For example, stimulation of sites extending in a columnar manner through lateral PAG evokes increases in blood pressure, heart rate, and sensory thresholds, as well as vocalization, locomotion, and aggression. Stimulation of a similarly organized column in ventrolateral PAG causes decreased blood pressure and heart rate, increased somatosensory thresholds, immobility, and defense (for review, see Lovick, 1985; Carrive and Bandler, 1991; Bandler and Shipley, 1994). The strongest autonomic, sensory, and motor changes are elicited from the caudal half to two-thirds of PAG. Thus, the anatomical organization of these functional columns corresponds very well to the columns of MPO afferents and Fos-positive PAG cells reported here. It is possible that MPO input to the PAG provides an anatomical substrate for the autonomic, sensory, and motor adjustments that occur during reproductive behavior. Because male reproductive behavior involves a strong motor component, including approach and courtship, mounting, intromission, pelvic thrusting, and ejaculation, it is possible that MPO efferents selectively engage neurons within the lateral PAG column while "turning off" the ventrolateral column during copulation. By contrast, after assuming the lordosis posture, the female remains relatively immobile. Thus, the converse may be true for females: the ventrolateral PAG column may be selectively engaged. However, because increases in nociceptive threshold and cardiovascular measures also accompany male and female sexual behavior, the lateral column may be involved in both genders.

\section{Could the MPO $\rightarrow$ PAG $\rightarrow$ RVM circuit mediate sexual behavior?}

MPO neurons are selectively excited during copulatory behavior. For example, mating behavior induces extensive Fos expression within the MPO of the male hamster (Fernandez-Fewell and Meredith, 1994). More than $90 \%$ of male rat MPO neurons show changes in firing rates during copulatory behavior (Shimura et al., 1994); $76 \%$ of the cells recorded showed increased activity during pelvic thrusting or immediately after intromission. A majority of MPO neurons are excited by stimulation of the dorsal penile nerve (Mallick et al., 1994).

In the anesthetized male rat, copulatory reflexes (erection and ejaculation) can be elicited only after spinal cord transection, suggesting that these reflexes are under tonic descending inhibitory control (Hart, 1968; Kurtz and Santos, 1979; Sachs and Britan, 1990). Neurotoxic lesions of the nucleus PGi at the caudal pole of the facial nucleus removed this inhibition (Marson and McKenna, 1990). Bilateral lesions of the nucleus PGi significantly 
reduced the latency to first copulatory reflex in the awake rat (Marson et al., 1992). The present results demonstrate that MPO stimulation induces Fos in PAG neurons that project to both the NRM and nucleus PGi. NRM and nucleus PGi project to the thoracic and lumbrosacral spinal cord, including to sympathetic and parasympathetic preganglionic regions involved in sexual reflexes (Holstege et al., 1979; Martin et al., 1985; Holstege and Tan, 1987; Shen et al., 1990; Marson et al., 1993). Thus, activation of the MPO, a forebrain region intimately involved in sexual behavior, excites a substantial population of PAG neurons that project to the medulla. Taken together with previous studies of the connections of NRM and nucleus PGi to the spinal cord, it is reasonable to conjecture that the $\mathrm{MPO} \rightarrow \mathrm{PAG} \rightarrow \mathrm{RVM}$ pathway functions, at least in part, to coordinately regulate the neuroendocrine, motor, and autonomic components necessary for the elaboration of sexual behaviors.

\section{REFERENCES}

Arendash GW, Gorski RA (1983) Effects of discrete lesions of the sexually dimorphic nucleus of the preoptic area or other medial preoptic regions on the sexual behavior of male rats. Brain Res Bull 10:147-154.

Bandler R, Carrive P (1988) Integrated defence reaction elicited by excitatory amino acid microinjection in the midbrain periaqueductal grey region of the unrestrained cat. Brain Res 439:95-106.

Bandler R, Carrive P, Zhang SP (1991) Integration of somatic and autonomic reactions within the midbrain periaqueductal grey: viscerotopic, somatotopic and functional organization. Prog Brain Res 87:269-305.

Bandler R, Shipley MT (1994) Columnar organization in the midbrain periaqueductal gray: modulcs for cmotional cxpression? Trends Neurosci $19: 379-389$

Behbehani MM, Fields HL (1979) Evidence that an excitatory connection between the periaqueductal gray and nucleus raphe magnus mediates stimulation produced analgesia. Brain Res 170:85-93.

Bloch GJ, Gorski RA (1988) Cytoarchitectonic analysis of the SDN-POA of the intact and gonadectomized rat. J Comp Neurol 275:604-612.

Bullitt E (1990) Expression of c-fos-like protein as a marker for neuronal activity following noxious stimulation in the rat. $\mathbf{J}$ Comp Neurol 296:517-530.

Carrive P, Bandler R (1991) Control of extracranial and hindlimb blood flow by the midbrain periaqueductal grey of the cat. Exp Brain Res 84:599-606.

Carrive P, Bandler R, Dampney RAL (1988) Anatomical evidence that hypertension associated with the defence reaction in the cat is mediated by a direct projection from a restricted portion of the midbrain periaqueductal grey to the subretrofacial nucleus of the medulla. Brain Res 460:339-345.

Carrive P, Bandler R, Dampney RAL (1989a) Somatic and autonomic integration in the midbrain of the unanesthetized decerebrate cat: a distinctive pattern evoked by excitation of neurones in the subtentorial portion of the midbrain periaqueductal grey. Brain Res 483:251-258.

Carrive P, Bandler R, Dampney RAL (1989b) Viscerotopic control of regional vascular beds by discrete groups of neurons within the midbrain periaqueductal gray. Brain Res 493:385-390.

Carrive P, Dampney RAL, Bandler R (1987) Excitation of neurones in a restricted portion of the midbrain periaqueductal grey elicits both behavioural and cardiovascular components of the defence reaction in the unanesthetised decerebrate cat. Neurosci Lett 81:273-278.

Carstens C, MacKinnon JD, Guinan MJ (1982) Inhibition of spinal dorsal horn neuronal responses to noxious skin heating by medial preoptic and septal stimulation in the cat. J Neurophysiol 46:981-991.

Chan RKW, Sawchenko PE (1994) Spatially and temporally differentiated patterns of c-fos expression in brainstem catecholaminergic cell groups induced by cardiovascular challenges in the rat. J Comp Neurol 348:433-460.

Clemens LG, Gladue BA (1979) Neuroendocrine control of adult sexual behavior. In: Reviews of neurosciences (Schneider DM, ed), pp 73-103. New York: Raven.

Davis PJ, Zhang SP, Bandler R (1993) Pulmonary and upper airway afferent influences on the motor pattern of vocalization evoked by excitation of the midbrain periaqueductal gray of the cat. Brain Res 607:61-80.

Day TA, Willoughby JO, Geffen LB (1979) Thermoregulatory effects of preoptic area injections of noradrenaline in restrained and unrestrained rats. Brain Res 174:175-179.

Docke F, Rhode W, Gerker P, Chaoui R, Dorner G (1984) Varying sensitivity to the negative oestrogen feedback during the ovarian cycle of female rats: evidence for the involvement of oestrogen and the medial preoptic area. J Endocrinol 102:287-294.

DonCarlos LL, Monroy E, Morrell JI (1991) Distribution of estrogen receptor-immunoreactive cells in the forebrain of the female guinea pig. J Comp Neurol 305:591-612.

Dragunow M, Faull R (1989) The use of c-fos as a metabolic marker in neuronal pathway tracing. J Neurosci Methods 29:261-265.

Edwards DA, Einhorn LC (1986) Preoptic and midbrain control of sexual motivation. Physiol Behav 37:329-335.

Erickson JT, Millhorn DE (1994) Hypoxia and electrical stimulation of the carotid sinus nerve induce Fos-like immunoreactivity within catecholaminergic and serotonergic neurons of the rat brainstem. J Comp Neurol 348:161-182.

Fernandez-Fewell GD, Meredith M (1994) c-fos expression in vomeronasal pathways of mated or pheromone-stimulated male golden hamsters: contributions from vomeronasal sensory input and expression related to mating performance. I Neurosci 14:3643-3654.

Gerfen CR, Sawchenko PE (1984) An anterograde neuroanatomical method that shows the detailed morphology of neurons, their axons and terminals: immunocytochemical localization of an axonally transported plant lectin, Phaseolus vulgaris leucoagglutinin (PHA-L). Brain Res 290:219-238.

Gorski RA, Harlan RE, Jacobson CD, Shryne JE, Southam AM (1980) Evidence for the existence of a sexually dimorphic nucleus in the preoptic area of the rat. J Comp Neurol 193:529-539.

Hansen S, Kohler C, Goldstein M, Steinbusch HVM (1982) Effects of ibotenic acid-induced neuronal degeneration in the medial preoptic area and the lateral hypothalamic area on sexual behavior in the male rat. Brain Res 239:213-232

Hart BL (1968) Sexual reflexes and mating behavior in the male rat. J Comp Physiol Psych 65:453-460.

Heimer L, Larrson K (1966) Impairment of mating behavior in male rats following lesions in the preoptic-anterior hypothalamic continuum. Brain Res 3:248-263.

Holstege G, Kuypers HGJM, Boer RC (1979) Anatomical evidence for direct brain stem projections to the somatic motoneuronal cell groups and autonomic preganglionic cell groups in cat spinal cord. Brain Res 171:329-333

Holstege G, Tan J (1987) Supraspinal control of motoneurons innervating the striated muscles of the pelvic floor including urethral and anal sphincters. Brain 110:1323-1344.

Hori T, Nakashima T, Koga H, Kiyohara T, Inoue T (1988) Convergence of thermal, osmotic and cardiovascular signals on preoptic and anterior hypothalamic neurons in the rat. Brain Res Bull 20:879-885.

Iloshina Y, Takeo T, Nakano K, Sato T, Sakuma Y (1994) Axon-sparing lesion of the preoptic area enhances receptivity and diminishes proceptivity among components of female rat sexual behavior. Behav Brain Kes 61:197-204.

Hsu SM, Raine L, Fanger H (1981) Use of avidin-biotin-peroxidase complex $(A B C)$ in immunoperoxidase techniques: a comparison between $\mathrm{ABC}$ and unlabeled antibody (PAP) procedures. J Histochem Cytochem 29:577-580.

Hunt SP, Pini A, Evan G (1987) Induction of c-fos-like protein in spinal cord neurons following sensory stimulation. Nature 328:632-634.

Jacobson CS, Terkel J, Gorski RA, Sawyer CH (1980) Effects of small medial preoptic area lesions on maternal behavior: retrieval and nest building in the rat. Brain Res 194:471-478.

Jones SL, Light AR (1990) Electrical stimulation in the medullary nucleus raphe magnus inhibits noxious heat-evoked fos protein-like immunoreactivity in the rat lumbar spinal cord. Brain Res 530:335-338.

Jürgens U (1991) Neurochemical study of PAG control of vocal behavior. In: The midbrain periaqueductal gray matter: functional, anatomical and neurochemical organization (Depaulis A, Bandler R, eds), pp 11-22. New York: Plenum.

Jürgens U, Pratt R (1979) Role of the periaqueductal grey in vocal expression of emotion. Brain Res 167:367-378.

Kalra SP, Kalra PS (1983) Neural regulation of luteinizing hormone secretion in the rat. Endocr Rev 4:311-351. 
Koyama Y, Hayaishi O (1994) Firing of neurons in the preoptic/anterior hypothalamic area in rat: its possible involvement in slow wave sleep and paradoxical sleep. Neurosci Res 19:31-38.

Krukoff TL, Morton TL, Harris KH, Jhamandas JH (1992) Expression of c-fos protein in rat brain elicited by clectrical stimulation of the pontine parabrachial nucleus. J Neurosci 12:3582-3590.

Kurtz RG, Santos R (1979) Supraspinal influences on the penile reflexes of the male rat: comparison of the effects of copulation, spinal transection and cortical spreading depression. Horm Behav 12:73-94.

Larson CR (1985) The midbrain periaqueductal gray: a brainstem structure involved in vocalization. J Speech Hear Res 28:241-249.

Larson CR, Kistler MK (1984) Periaqueductal gray neuronal activity associated with laryngeal EMG and vocalization in the awake monkey. Neurosci Lett 46:261-266.

Larson CR, Kistler MK (1986) The relationship of periaqueductal gray ncurons to vocalization and laryngcal EMG in the bchaving monkcy. Exp Brain Res 63:596-606.

Liebeskind JC, Guilbaud G, Besson J-M, Oliveras J-L (1973) Analgesia from electrical stimulation of the periaqueductal gray matter in the cat: behavioral observations and inhibitory effects on spinal cord interneurons, Brain Res 50:441-446.

Lin JS, Sakai K, Jouvet M (1994) Hypothalamo-preoptic histaminergic projections in sleep-wake control in the cat. Eur J Neurosci 6:618-625.

I isk RD (1966) Inhibitory centers in sexual behavior in the male rat. Science 152:669-670.

Lisk RD, MacGregor L (1982) Subproestrous estrogen levels facilitate lordosis following septal or cingulate lesions. Neurocndocrinology 35:313-320.

Lovick TA (1985) Ventrolateral medullary lesions block the antinociceptive and cardiovascular responses elicited by stimulating the dorsal periaqueductal grey matter in rats. Pain 21:241-252.

Lovick TA (1990) Selective modulation of the cardiovascular response but not the antinociception evoked from the dorsal PAG, by 5-HT in the ventrolateral medulla. Pflugers Arch 416:222-224.

Mallick HN, Manchanda SK, Kumar VM (1994) Sensory modulation of the medial preoptic area neuronal activity by dorsal penile nerve stimulation in rats. J Urol 151:759-762.

Malsbury CW, Pfaff DW, Malsbury AM (1981) Suppression of sexual receptivity in the female hamster: neuroanatomical projections from preoptic and anterior hypothalamic electrode sites. Brain Res 181:267-284.

Mancia G, Zanchetti A (1981) Hypothalamic control of autonomic functions. In: Handbook of the hypothalamus, Vol 3, Pt B, behavioral studies of the thalamus (Panksepp P, ed), pp 147-201. New York: Dekker.

Manning JW, Hartle DK, Ammons WS, Koyama S (1985) The median preoptic area in cardiovascular reflex activity. J Auton Nerv Syst 12:239-249.

Marson L, List MS, McKenna KE (1992) Lesions of the nucleus paragigantocellularis alter ex copula penile reflexes. Brain Res 592:187-192.

Marson L, McKenna KE (1990) The identification of a brainstem site controlling spinal reflexcs in malc rats. Brain Res 515:303-308.

Marson L, Platt KB, McKenna KE (1993) Central nervous system innervation of the penis as revealed by the transneuronal transport of pseudorabies virus. Neuroscience 55:263-280.

Martin GF, Vertes RP, Waltzer R (1985) Spinal projections of the gigantocellular reticular formation in the rat: evidence for projections from different areas to laminae I and II and lamina IX. Exp Brain Res 58:154-162.

McCarthy MM, Malik KF, Feder HH (1990) Increased GABAergic transmission in medial hypothalamus facilitates lordosis but has the opposite effect in preoptic area. Brain Res 507:40-44.

McGinty D, Szymusiak R (1990) Keeping cool: a hypothesis about the mechanisms and functions of slow-wave sleep. Trends Neurosci $13: 480-487$.

Menétrey D, Basbaum AI (1989) Colloidal gold conjugates for retrograde neuronal tracing. In: Colloidal gold: principles, methods, and applications, Vol 2, pp 203-226. New York: Academic.

Morgan JI, Curran T (1986) Role of ion flux in the control of c-fos expression. Nature 322:552-555.

Morgan MM, Liebeskind JC (1987) Site specificity in the development of tolerance to stimulation-produced analgesia from the periaqueductal gray matter of the rat. Brain Res 425:356-359.

Moss RL, Paloutzian RF, Law OT (1974) Electrical stimulation of forebrain structures and its effects on copulatory as well as stimulus-bound behavior in ovariectomized hormone-primed rats. Physiol Behav 12:997-1004

Murphy AZ, Ennis M, Rizvi TA, Behbehani MM, Shipley MT (1995) Fos expression induced by changes in arterial pressure is localized in dislincl, longitudinally organized columns of neurons in the rat midbrain periaqueductal gray. J Comp Neurol 360:286-300.

Murphy AZ, Ennis M, Shipley MT, Behbehani MM (1994a) Anatomical organization of pressor-depressor columns in the rat midbrain periaqueductal gray (PAG). Soc Neurosci Abstr 20:297.

Murphy AZ, Ennis M, Shipley MT, Behbehani MM (1994b) Directionally specific changes in arterial pressure induce differential patterns of Fos expression in discrete areas of the rat brainstem: a double-labeling study for Fos and catecholamines. J Comp Neurol 349:36-50.

Nance DM, Christensen LW, Shryne J, Gorski RA (1977) Modifications in gonadotropin control and reproductive behavior in the female rat by hypothalamic and preoptic lesion. Brain Res Bull 2:307-321.

Ogawa S, Kow L-M, McCarthy MM, Pfaff DW, Schwartz-Giblin S (1991) Midbrain PAG control of female reproductive behavior: in vitro electrophysiological characterization of actions of lordosis-relevant substances. In: The midbrain periaqueductal gray matter (Depaulis A Bandler R, eds), pp 211-235. New York: Plenum.

Oliveras JL, Woda A, Guilbaud G, Besson JM (1974) Inhibition of the jaw opening reflex by electrical stimulation of the periaqueductal gray matter in the awake, unrestrained cat. Brain Res 72:328-331.

O'Neill TP, Brody MJ (1987) Role for the median preoptic nucleus in centrally evoked pressor responses. Am J Physiol 252:R1165-R1172.

Pfaff DW, Sakuma Y (1979) Facilitation of the lordosis reflex of female rats from the ventromedial nucleus of the hypothalamus. J Physiol (Lond) 288:189-202.

Pfaff DW, Schwartz-Giblin S (1988) Cellular mechanisms of female reproductive behaviors. In: The physiology of reproduction, Vol 2 (Knobil E, Neill J, eds), pp 1487-1568. New York: Raven.

Powers B, Valenstein ES (1972) Sexual receptivity: facilitation by medial preoptic lesions in female rats. Science 175:1003-1005.

Presley RW, Menétrey D, Levine JD, Basbaum AI (1990) Systemic morphine suppresses noxious stimulus-evoked fos protein-like immunoreactivity in the rat spinal cord. J Neurosci 10:323-335.

Reichling DB, Kwait GC, Basbaum AI (1988) Anatomy, physiology and pharmacology of the periaqueductal gray contribution to antinociceptive controls. In: Progress in brain research, Vol 77 (Fields HI, Besson JM, eds), pp 31-46. Amsterdam: Elsevier.

Reynolds DV (1969) Surgery in the rat during electrical analgesia induced by focal brain stimulation. Science 164:444-445.

Rizvi TA, Ennis M, Aston-Jones G, Jiang M, Liu W-L, Behbehani MM, Shipley MT (1994) Preoptic projections to Barrington's nucleus and the pericoerulear region: architecture and terminal organization. $J$ Comp Neurol 347:1-24.

Rizvi TA, Ennis M, Shipley MT (1992) Reciprocal connections between the medial preoptic area and the midbrain periaqueductal gray in rat: a WGA-HRP and PHA-L study. J Comp Neurol 315:1-15.

Roberts DW, Martin JR (1977) Effects of lesions in central thermosensitive areas in thermoregulatory responses in rats. Physiol Behav 19:503-511.

Rodriguez-Sierra JF, Terasawa E (1979) Lesions of the preoptic area facilitate lordosis behavior in male and female guinea pigs. Brain Res Bull 4:513-517.

Sachs BD, Meisel RL (1988) The physiology of male sexual behavior. In: The physiology of reproduction, Vol 2 (Knobil E, Neill J, eds), pp 1393-1485. New York: Raven.

Sachs BL, Britan D (1990) Spinal block reveals roles for brain and spinal cord in the mediation of reflexive penile erections in rats. Brain Res 528:99-108.

Sakuma Y, Pfaff DW (1979a) Facilitation of female reproductive behavior from mesencephalic central gray in the rat. Am J Physiol 237:R278-R284.

Sakuma Y, Pfaff DW (1979b) Mesencephalic mechanisms for integration of female reproductive behavior in the rat. Am $J$ Physio 237:R285-R290.

Scammell TE, Price KJ, Sagar SM (1993) Hyperthermia induces c-fos expression in the preoptic area. Brain Res 618:303-307.

Sharp FR, Sagar SM, Hicks K, Lowenstein D, Hisanaga K (1991) c-fos mRNA, Fos, and Fos-related antigen induction by hypertonic saline and stress. J Neurosci 11:2321-2331. 
Shen P, Arnold AP, Micevych PE (1990) Supraspinal projections to the ventromedial lumbar spinal cord in adult malc rats. J Comp Ncurol 300:263-272

Sheng M, Greenberg ME (1990) The regulation and function of c-fos and other immediate early genes in the nervous system. Neuron $4: 477-485$.

Shimura T, Yamamoto T, Shimokochi M (1994) The medial preoptic area is involved in both sexual arousal and performance in male rats: re-evaluation of neuron activity in freely moving animals. Brain Res 640:215-222.

Shipley MT, Luna J, McLean JH (1989) Processing and analysis of neuroanatomical images. In: Neuroanatomical tract tracing methods 2 (Heimer L, Zaborsky L, eds), pp 331-388. New York: Plenum.

Shipley MT, Murphy AZ, Rizvi TA, Ennis M, Behbehani MM (1995) Olfaction, reproduction and the emotional motor system. Prog Brain Res, in press.

Simerly RB, Chang C, Muramatsu M, Swanson LW (1990) Distribution of androgen and estrogen receptor mRNA-containing cells in the rat brain: an in situ hybridization study. J Comp Neurol 294:76-95.

Simerly RB, Swanson LW, Gorski RA (1984) Demonstration of a sexual dimorphism in the distribution of serotonin-immunoreactive fibers in the medial preoptic nucleus of the rat. J Comp Neurol 225:151-166.

Swanson LW, Kucharczyk J, Mogenson GJ (1978) Autoradiographic evidence for pathways from the medial preoptic area to the midbrain involved in the drinking response to angiotensin II. J Comp Neurol 178:645-659.
Swanson LW, Mogenson GJ (1981) Neural mechanisms for the functional coupling of autonomic, endocrine and somatomotor responses in adaptive behaviors. Brain Res Rev 3:1-34.

Takeo T, Chiba Y, Sakuma Y (1993) Suppression of the lordosis reflex of female rats by efferents of the medial preoptic area. Physiol Behav 53:831-838.

Van Bockstaele EJ, Aston-Iones G, Pieribone VA, Ennis M, Shipley MT (1991) Subregions of the periaqueductal gray topographically innervate the rostral ventral medulla in the rat. J Comp Neurol 309:305-327.

Vellucci SV, Parrott RF (1994) Hyperthermia-associated changes in Fos protein in the medial preoptic and other hypothalamic nuclei of the pig following intravenous administration of prostaglandin E2. Brain Res 646:165-169.

Verberne AJM, Guyenet PG (1992) Midbrain central gray: influence on medullary sympathoexcitatory neurons and the baroreflex in rats. Am J Physiol 263:R24-R33.

Wang SC, Ranson SW (1941) The rolc of thc hypothalamus and preoptic region in the regulation of heart rate. Am J Physiol 132:5-8.

Zasorin NL, Malsbury CW, Pfaff DW (1975) Suppression of lordosis in hormone-primed female hamster by electrical stimulation of the septal area. Physiol Behav 14:595-599.

Zimmer LA, Ennis M, El-Etri M, Shipley MT (1993) Diagonal band stimulation induced Fos \& seizures in piriform cortex are blocked by scopolamine. Soc Neurosci Abstr 19:913. 